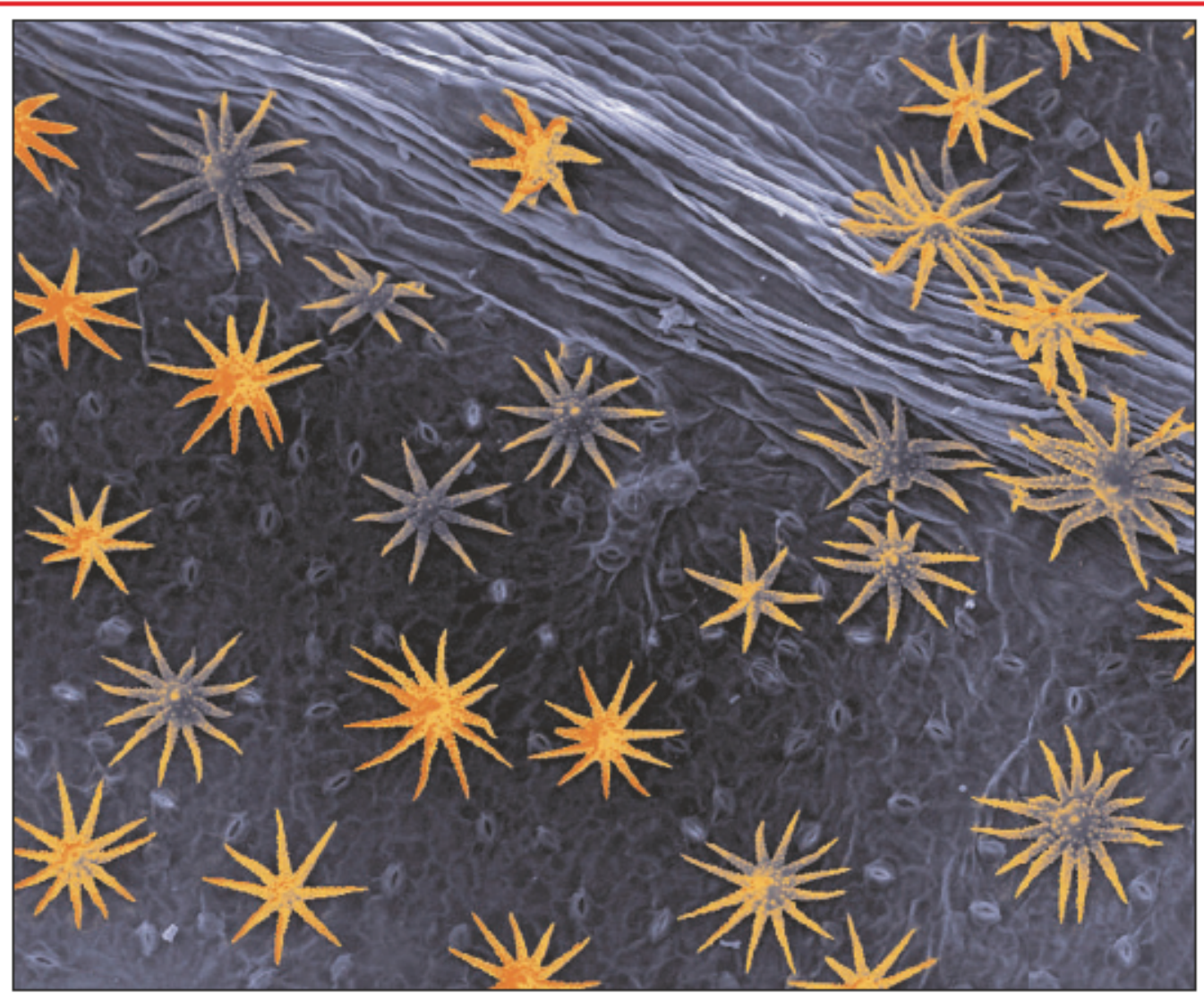

\title{
SNAPSHOT Judges fall for a leaf's star quality
}

\author{
These are not orange starfish on \\ the sea floor but tiny hairs on \\ the underside of a plant's leaf. \\ Known as trichomes, the hairs \\ help the leaf to fend off the \\ attentions of hungry insects \\ and parasites. This image, \\ taken using a scanning \\ electron microscope, was highly \\ commended in the Novartis and \\ The Daily Telegraph Visions of \\ Science competition, the results \\ of which weredue to be \\ announced on 28 September. \\ The photographer is Stephanie \\ Schüller of the Centre for \\ Paediatric Gastroenterology \\ at University College London, \\ who captured the im age while \\ teaching a student how to use \\ the micros cope.
}

\section{Europe tells Russia it faces HIV ruin}

Health experts from Europe and the United States have called on the Russian government to strengthen its fight against the country's dramatically worsening HIV and AIDS problem. The epidemic there is set to explode, posing a serious threat to the former superpower's social and economic welfare, and even its stability, they told a parliamentary hearing at the Russian State Duma on 23 September.

${ }^{\alpha}$ Russia needs to do a lot more than it has done in the past," says Chris McCafferty, chairwoman of a Council of Europe committee on social affairs that is launching a detailed study of HIV and AIDS in Europe. The committee is starting with Russia, and organized the Duma hearing as a first step. "It's bizarre," she says. "Sex is for sale on every corner here, but a sexual-health strategy just doesn't seem to exist."

AIDS arrived late in Russia, thanks to the country's relative isolation during the cold war, and the first case of HIV was not reported until 1987. But the epidemic is now believed to be growing faster in Russia and central Asia than anywhere else in the world.

According to official statistics, some 330,000 people have been infected so far, but little research has been done into the extent of the epidemic, and there is no credible reporting system for new cases. The number of unreported cases is thought to exceed 1 million.

As elsewhere, the disease first infected injecting drug users and sex workers, groups that often overlap. But it now seems to be moving into a second wave, where HIV is passed more by sexual transmission than shared needles.

The fear is that within five years, up to 10 million of Russia's 140-million population could be infected, says Alec

Khachatrian, Russian programme director of Transatlantic Partners Against AIDS (TPAA), a New York, Moscow and Kiev-based charity that gave evidence at the hearing. Large-scale action is urgently needed to prevent the disease spreading from vulnerable groups to the general population, he says. "Neither AIDS prevention and treatment, nor research related to the disease, have been big priorities here."

In recent years the Russian government has spent just US\$3 million to $\$ 4$ million a year fighting the disease. In comparison, Brazil, whose population is about the same size, spends almost $\$ 200$ million a year. Most Russian AIDS programmes are run by nongovernmental and international organizations, such as the World Health Organization or the Bill \& Melinda Gates Foundation.

Last week, the Russian Health Ministry proposed spending up to $\$ 90$ million extra each year. Among other things, this would provide people with AIDS with antiretroviral treatment, which can cost up to $\$ 10,000$ per person per year.

But Khachatrian feels that this would be far from enough. "What's really needed is a single AIDS strategy spanning research, prevention, treatment and human rights," he says. In an open letter to Russian president Vladimir Putin, the TPAA has asked for the creation of a presidential council on HIV and AIDS that would develop and review such a strategy.

Quirin Schiermeier 